\title{
Portuguese translation and validation of the body-esteem scale for adolescents and adults (BESAA) in university students
}

\author{
Maria Piedade Brandão ${ }^{1,2, *}$, Vera Vale ${ }^{3}$, Margaret Gomes ${ }^{4}$ and Anabela Pereira ${ }^{2,5}$ \\ 1 School of Health, University of Aveiro; mpiedade@ua.pt \\ 2 Center for Health Technology and Services Research, University of Porto \\ 3 Department of Economics, Management, Industrial Engineering and Tourism, University of Aveiro; \\ vcvale@ua.pt \\ 4 Department of Languages and Cultures, University of Aveiro; mgomes@ua.pt \\ 5 Department of Education and Psychology, University of Aveiro; anabelapereira@ua.pt \\ * Correspondence: mpiedade@ua.pt; Tel.: +351927992277
}

\begin{abstract}
Body-Esteem Scale is an assessment tool for adolescents and adults that evaluate three dimensions of self-evaluations of one's body. Body-Esteem Scale has been translated and validated in some countries since America down to Europe. Lack of translation and reliability evidence in Portugal was detected. This study aimed to translate and test the validity and reliability of the Body Esteem Scale for Adolescents and Adults (BESAA) in students in the context of Portuguese higher education. A total of 173 students $(60.7 \%$ are female) with a mean age of 19.7 (standard deviation $=$ 2.2) years participated. Categorical Principal Component Analysis was used to assess the underlying dimensions of BESAA. Construct validity was evaluated through correlation with the Appearance Schemas Inventory - Revised and a three-factor model ("Appearance", "Weight" and "Attribution") was established. Confirmatory factor analysis was performed to verify the construct validity of the instrument. Items that had factor weights $(\lambda)<.40$ were removed, as well as those that were considered redundant by the modification indices estimated by the Lagrange Multipliers (LM) method (LM>11, p<.001). We observed high correlations between theoretically similar factors, and low correlations between different factors. The Portuguese BESAA showed adequate validity and reliability.
\end{abstract}

Keywords: validity; reliability; assessment; body image; self-evaluation; students

\section{Introduction}

Body image (BI) is an important factor that has a strong influence on the wellbeing of people. Many consequences have resulted over time from low self-perception of BI, namely an increase in the prevalence of eating disorder risk [1], increased rates of anorexia [2] and bulimia [3].

Some researchers have investigated gender related-body satisfaction / dissatisfaction and the involvement of BI in the body self-assessment process [4-6]. The results have shown that gender and age are two factors that affect the feeling of body satisfaction, with women being more dissatisfied than men, mainly during adolescence [7]. Despite these differences, the desire to modify their shape or weight is common to both sexes.

Literature has also shown that concerns about the body are not limited to age or sex, but also to changes in lifestyle. The period of life where many changes occur is in the transition between academic cycles, especially from secondary to higher education, due to social and cultural changes [8-10]. Recent studies conducted with university students have demonstrated a strong association between BI and health indicators, namely body 
mass index (BMI), showing that individuals with extreme BMI values (thinness or obesity), presented significantly greater dissatisfaction with BI, irrespective of gender[11-13].

It is well known that health status perception and behavior are important factors that have a strong influence on the wellbeing of citizens and societies. To investigate how BI perception may influence health-related behavior among university students in higher educations it is necessary to apply valid and reliable instruments. Although there are psychometric investigations of body esteem measurement in the literature, only six studies are known [14] to assess measurement properties with Body Esteem Scale for Adolescents and Adults (BESAA) [15-19]. Unfortunately, to our knowledge, there is no Portuguese version of BESAA, namely in the context of higher education.

In Portugal, research carried out with university students has focused on the evaluation of the cognitive component, namely on their investment in their appearance [20]. However, the literature contains many instruments that measure and assess the self-evaluation of body perception, many of which focus on different dimensions, such as body satisfaction [21], self-evaluation of BI [22] or appearance [23]. Nevertheless, Mendelson and her collaborators [16], offer us the possibility of evaluating three dimensions of self-evaluation of BI in a single instrument: (i) feelings about appearance, (ii) satisfaction with weight, and (iii) evaluations attributed by other people about the body and the appearance of whoever is being evaluated [16]. BESAA is an instrument to assess the feelings underlying $\mathrm{BI}$ and not only its physical perception.

Considering the specific characteristics related to university students, the aim of this study was to adapt and validate the BESAA. The specific aims of the study were to translate and adapt the BESAA original by Mendelson, Mendelson \& White [16], to a Portuguese setting, according to International Test Commission Guidelines [24] and to analyze psychometric properties to determine the usefulness of the BESAA in a sample of Portuguese higher education students.

\section{Materials and Methods}

\subsection{Participants}

The participants were drawn from a university in central Portugal during the 2016/2017 academic year. The university currently offers 56 degree programs and has 16 departments, one institute of higher education and three polytechnics.

The sample is made up of first cycle university students from seven scientific areas (Economy and Management, Sciences, Engineering, Communication \& Art, Languages, Education and Health). According to the number of students in each area, 18 courses were randomly selected [25-26]. One class was randomly selected from each year of each degree and the students were invited to participate in the study. The degrees were then grouped into three areas, based on previous studies carried out [8]: (i) Human and Social Sciences, (ii) Technical and Natural Sciences and (iii) Health Sciences.

The sample size was estimated considering a minimum subject to item ratio of at least five subjects per variable [25-26]. Inclusion criteria were 18 years of age or older and without physical disability, diminished visual efficiency or psychopathologies associated with BI (e.g. anorexia nervosa and bulimia nervosa). This cross-sectional study (pilot study) consisted of 173 participants (60.7\% are female), aged between 18 and 32 years (mean age $19.7 \pm 2.2$ ), recruited at a university in central Portugal during the 2016/2017 academic year.

\subsection{Adaptation of the instrument}


The BESAA is a self-response scale composed of 23 items in a 5-point Likert scale format ranging from 0 (never) to 4 (always). In this scale, negative items $(4,7,9,11,13,17$, 18, 19 and 21) were reverted [16, 19]. BESAA consists of three dimensions or subscales, namely Appearance, Weight, and Attribution: i) the Appearance subscale allows the evaluation of a person's feelings about their appearance, ii) the Weight subscale, which evaluates satisfaction with body weight and iii) the Attribution subscale, which evaluates a person's perception of others' assessment of their body and appearance. The Cronbach alpha values obtained in the first version for each of the subscales were $0.92,0.94$, and 0.81 respectively [16]. These values indicate very good internal consistency and demonstrate that the scale is replicable.

Precondition guidelines. The adapted Portuguese BESAA maintained the three dimensions and the same number of items which are in the original version.

Development guidelines: Item translation and pilot study. The translation, back-translation procedures and the semantic validation were carried out in accordance with work carried out by other authors [24, 27-28]. Initially, all the original items were translated into Portuguese by two bilingual translators (a physiotherapist and a nurse whose first language was Portuguese), resulting in the first version of the BESAA (version A). Following this, version A was subject to retroversion by another bilingual person (whose first language was English but without having access to the original version), resulting in version B. Version B of the Portuguese BESAA was compared to the original and submitted to semantic (e.g. verb tenses and colloquial language), social and cultural discussion among the authors of this study, the native English person and the two health professionals. Thus, it was possible to identify and bridge any existing discrepancies between the original and Portuguese version. Five questions from the retroversion were subject to discussion: Question 5 (I think my appearance will help me get a job), Question 9 (I wish I were more good looking), Question 14 (I am as good looking as most other boys/girls), question 15 (I am very happy with my appearance) and Question 20 (My appearance helps me to get a boyfriend/girlfriend). The discussion gave rise to the following changes: question 5 ('would help' was changed to 'will help' to make the possible future result more tangible), question 9 ('looked better' was changed to 'good looking' to reinforce the idea of attractiveness), Question 14 ('people' was altered to 'boys/girls' to create the connotation of a romantic connection), question 15 ('pretty happy' in the original version means 'quite happy' but the desired connotation was 'very happy') and question 20 ('to get dates' means 'possibly amorous' but not necessarily, so it was changed to 'boyfriend/girlfriend' to give the idea of a more serious relationship). The result of the discussion and its amendments resulted in version $C$ of the Portuguese BESAA. The following stage was to carry out a pre-test with the final version of the BESAA with three undergraduate students (18, 20 and 21 years old) from another university in order to ensure that the questions were clear and to identify possible errors or discrepancies in the questionnaire. Not having found any ambiguity, errors or discrepancies in the final version of the Portuguese BESAA, the descriptive and psychometric properties were evaluated.

Confirmation guidelines. The International Test Commission requires the equivalence of any new and adapted version of an original scale in terms of data collection, psychometric properties, reliability and validation. These parameters and analyses are reported in the "Results" section of this study.

Administration guidelines. The study was approved by an Ethics Committee with the local code 9/2016, on April 13, 2016. Before the data collection, all participants were informed about the objectives of the study in their classrooms by researchers and were invited to respond to three questionnaires (survey) on an online platform created for this purpose. Each student answered the questionnaires in the following order: i) a specific 
questionnaire for university students designed to collect general data on social and demographic characteristics and history of concern for BI (e.g. anorexia and bulimia), ii) the Portuguese BESAA after linguistic validation and iii) the Appearance Schemas Inventory - Revised [ASI-R] of personal beliefs about appearance using the Portuguese version of the ASI-R [20], which is a 20-item, two-dimensional, self-administered scale covering two facets (subscales) of schematic investment in appearance: self-evaluative and motivational salience of appearance. The items are rated on a 5-point Likert scale where 1 indicates very poor investment in appearance and 5 indicates a very high investment in appearance (high scores demonstrate greater schematic investment levels related to appearance). In the Portuguese ASI-R version, Cronbach's alpha values were 0.76 for the self-evaluative subscale and 0.73 for the motivational salience subscale [20]. Permission to use the BESAA and the ASI-R instruments was obtained from the authors.

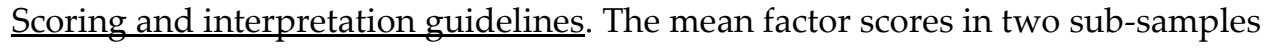
were compared using two criteria: (i) gender (male/female) and (ii) area (Technical and Natural Sciences/Human and Social Sciences/Health Sciences) (see Results section).

Documentation guidelines. The guidelines suggested [24] were followed in order to interpret the scores of the BESAA for future research and have been discussed (see Discussion section).

\subsection{Data Analysis}

The SPSS (version 22.0) was used for statistical analysis. Two-sided significance tests at the $5 \%$ level were used. The percentages from categorical variables and means and standard deviation (mean $\pm \mathrm{SD}$ ) from quantitative variables were presented.

The psychometric characterization of the Portuguese BESAA version was performed through item analysis (e.g. item-total correlation), factorial analysis and reliability (Cronbach's alpha).

To estimate instrument reliability, Cronbach's alpha, corrected item-total correlations, and inter-item correlations were used with the following criterion: factor extractions/dimensions with a Cronbach's alpha greater than or equal to 0.70 should be retained. The retaining criteria established in advance for the selection of factor items were: (i) factor loading of 0.5 or higher, (ii) presence of at least three items for one factor and (iii) interpretability. Four items with problems were excluded after the Corrected Item-Total Correlation calculation (items < .3) [29-30].

Categorical Principal Components Analysis (CAPTCA) and factor analysis with oblique rotation were performed [30] to explore the underlying dimensions of the Portuguese BESAA items (without the four excluded items). Oblique rotation was used, following what other researchers have shown, indicating that the dimensions of the BESAA were intercorrelated [16]. On decision of extraction of the number of factors it was also considered that factors with eigenvalues greater than 1 should be retained[29-30].

After having been computed, a three-factor solution was yielded. As two factor (items 3 and19) loading did not univocally load on one component, they were deleted. The analysis was recomputed without the seven items and the recomputed analysis showed the three-factor solution again where one factor loading did not load on one component in item 22, which is why it was also withdrawn. The analysis was recomputed without the eight items and yielded the three-factor solution with adequate factor loadings (> .50) for the all retained items ( 8 items in the first factor, 4 items in the second 
and 3 items in the third). Following on from this analysis, 15 items were obtained for the final version of the Portuguese BESAA.

Construct validity was performed based on the analysis of Pearson correlations computed between the BESAA and the Appearance Schemas Inventory - Revised (ASI-R) [20, 31]. The following interpretations for the correlation coefficients were used: (i) values greater than 0.50 indicated a large correlation, (ii) values between 0.30 and 0.49 showed a moderate correlation and (iii) values between 0.10 and 0.29 implied a small correlation.

The construct validity of the instrument was estimated by measuring factorial, convergent and discriminant validity. We conducted confirmatory factor analysis-CFA (with first order and second order model), the Weighed Least Squares Mean and Variance Adjustment using AMOS software.

To evaluate fitness for purpose, we considered the following adequate measurements: the chi-square ratio by degrees of freedom $(\chi 2 / \mathrm{df}), \mathrm{CFI}$ and RMSEA as indices, according to Marôco [32]. The model's fit was considered adequate when $\chi 2 / \mathrm{df} \leq 2.0, \mathrm{CFI}$ and TLI $\geq .9$, and RMSEA $\leq .08$, (see Hair et al. [33] and Marôco [32]). Items that had factor weights $(\lambda)<.40$ were removed, as well as those that were redundant by the modification indices estimated by the Lagrange Multipliers (LM) method (LM>11, p<.001). Following Marôco [32], the modification indices were also used to verify the correlation between the item errors.

\section{Results}

Table 1 shows Cronbach's alphas, means and standard deviations for each Portuguese BESAA subscale for males and females for each area of study. Cronbach's alphas ranged from 0.60 to 0.96 , indicating acceptable to very good internal consistency for the three subscales for both sexes in all academic areas. Higher values for a particular dimension suggest a more positive BI. Overall, the means for females tended to be equal or slightly higher than 2 (in some cases), except for the "Attribution" subscale in the area of "Health sciences", where it is lower than 2. The average for males is higher than for females and close to 3 (often), mainly in the "Appearance" subscale.

Table 1. Cronbach's Alphas, Means, and Standard Deviations of Portuguese BESAA Subscales for Male and Female Participants at Different Scientific Area

\begin{tabular}{|c|c|c|c|c|c|c|c|c|c|}
\hline \multirow[b]{3}{*}{ Subscale and Scientific area } & & \multicolumn{8}{|c|}{ Gender } \\
\hline & & \multicolumn{4}{|c|}{ Male } & \multicolumn{4}{|c|}{ Female } \\
\hline & & $\alpha$ & M & SD & $\mathrm{n}$ & $\alpha$ & M & SD & $\mathrm{n}$ \\
\hline \multicolumn{10}{|l|}{ BES (Appearance) } \\
\hline & Technical and natural & & & & & & & & \\
\hline & sciences & .89 & 2.7 & .7 & 52 & .93 & 2.5 & .7 & 17 \\
\hline & Human and social & & & & & & & & \\
\hline & sciences & .67 & 2.7 & .3 & 5 & .96 & 2.3 & 1.0 & 23 \\
\hline & Health sciences & .95 & 2.6 & 1.0 & 11 & .92 & 2.3 & .7 & 65 \\
\hline & Total & .90 & 2.7 & .7 & 68 & .93 & 2.4 & .8 & 105 \\
\hline \multicolumn{10}{|l|}{ BES (Attribution) } \\
\hline & Technical and natural & .88 & 2.4 & .9 & 52 & .80 & 2.2 & .8 & 17 \\
\hline
\end{tabular}


sciences

Human and social

$\begin{array}{rrrrrrrrr}\text { sciences } & .67 & 2.5 & .6 & 5 & .94 & 2.0 & 1.2 & 23 \\ \text { Health sciences } & .83 & 2.4 & 1.0 & 11 & .91 & 1.8 & 1.0 & 65 \\ \text { Total } & .87 & 2.4 & .9 & 68 & .91 & 1.9 & 1.0 & 105\end{array}$

BES (weigh)

Technical and natural

$\begin{array}{lllllllll}\text { sciences } & .80 & 2.3 & .7 & 52 & .72 & 2.4 & .5 & 17\end{array}$

Human and social

$\begin{array}{lllllllll}\text { sciences } & .60 & 2.6 & .1 & 5 & .70 & 2.4 & .6 & 23\end{array}$

$\begin{array}{lllllllll}\text { Health sciences } & .87 & 2.3 & 1.0 & 11 & .78 & 2.4 & .6 & 65\end{array}$

$\begin{array}{lllllllll}\text { Total } & .80 & 2.4 & .7 & 68 & .75 & 2.4 & .5 & 105\end{array}$

Table 2 summarizes the socio-demographic characteristics of the 173 participants, $60.7 \%$ of whom were female. Almost all the participants were single $(99.4 \%)$ and had no related BI diseases (93.1\%). The participants were mostly 1st year students $(76.3 \%)$. The most represented area of study was the Health Sciences (43.9\%) followed by the Technical and Natural Sciences (39.9\%).

Table 2. Socio-demographic characteristics of the participants $(\mathrm{N}=173)$

n

$19.7 \pm 2.2$

Age, mean \pm SD

Female

105

60.7

Marital status

Single

172

99.4

Married

1

0.6

Scientific area

Technical and natural sciences

69

39.9

Human and social sciences

28

16.2

Health sciences

76

Study year

1st year

2nd year

20.2

other
$\%$

7


The descriptive analysis of the items of the Portuguese BESAA gave information about whether all response options were considered by the participants (see Table 3). In the majority of the questions (questions 11, 13,17 and 19 are exceptions) of the BESAA, about one-third ( $>30.1 \%$ ) of the participants opted to choose the 3rd item (sometimes) as a response. Moreover, another third of the participants $(>30.6 \%)$, also selected the option "often" in questions 1, 2, 5, 6, 12, 14, 15, 21 and 23. There are however, some exceptions in some of the questions, namely: (i) question 11 (I wish I looked like someone else), where more than a third of the participants selected the item "never" (35.3\%), (ii) question 17 (I feel ashamed of how I look) and question 19 (My weight makes me unhappy), where more than a third of participants selected the item "never" (> 34.1\%) and about a third selected "rarely" (> 30.1\%) as a response and (iii) question 16 (I feel I weigh the right amount for my height), $32.9 \%$ of participants selected only "often" as an alternative of response.

The CATPCA approach was using to identify the factor model for the Portuguese participants. A three-factor solution was suggested, by both the eigenvalue $(>1.0)$ and the internal consistency criterion. The first component explained $48.4 \%$ of the total variance, the second explained $12.6 \%$ and the third explained $6.6 \%$. This means that the three selected components explain $67.7 \%$ of the variance.

Table 3. Descriptive of the items of the Portuguese BESAA (N=173)

\begin{tabular}{|c|c|c|c|c|}
\hline Code & Item & Categories & $\mathbf{n}$ & $\%$ \\
\hline \multirow{6}{*}{1} & \multirow{6}{*}{$\begin{array}{l}\text { I like what I look like in pictures } \\
\text { (Gosto da minha aparência nas } \\
\text { fotografias.) }\end{array}$} & 1- Never & 1 & 0.6 \\
\hline & & 2- Rarely & 23 & 13.3 \\
\hline & & 3- Sometimes & 85 & 49.1 \\
\hline & & 4- Often & 55 & 31.8 \\
\hline & & 5- Always & 9 & 5.2 \\
\hline & & 1- Never & 1 & 0.6 \\
\hline \multirow{4}{*}{2} & \multirow{4}{*}{$\begin{array}{l}\text { Other people consider me good } \\
\text { looking (As outras pessoas } \\
\text { consideram--me bonito(a).) }\end{array}$} & 2- Rarely & 11 & 6.4 \\
\hline & & 3- Sometimes & 79 & 45.7 \\
\hline & & 4- Often & 69 & 39.9 \\
\hline & & 5- Always & 13 & 7.5 \\
\hline \multirow{6}{*}{3} & \multirow{5}{*}{$\begin{array}{l}\text { I'm proud of my body (Tenho } \\
\text { orgulho no meu corpo.) }\end{array}$} & 1- Never & 3 & 1.7 \\
\hline & & 2- Rarely & 31 & 17.9 \\
\hline & & 3- Sometimes & 73 & 42.2 \\
\hline & & 4- Often & 47 & 27.2 \\
\hline & & 5- Always & 19 & 11.0 \\
\hline & \multirow{5}{*}{$\begin{array}{l}\text { I am preoccupied with trying to } \\
\text { change my body weight (Estou } \\
\text { preocupado(a) em tentar mudar o } \\
\text { meu peso corporal.) }\end{array}$} & 1- Always & 13 & 7.5 \\
\hline \multirow{4}{*}{4} & & 2- Often & 45 & 26.0 \\
\hline & & 3- Sometimes & 54 & 31.2 \\
\hline & & 4- Rarely & 44 & 25.4 \\
\hline & & 5- Never & 17 & 9.8 \\
\hline 5 & I think my appearance would help & 1- Never & 11 & 6.4 \\
\hline
\end{tabular}


me get a job (Eu acho que a minha 2- Rarely 20

11.6

aparência pode ajudar-me a arranjar 3- Sometimes 61

35.3

um emprego.)

4- Often 60

34.7

5- Always

12.1

1- Never

1.2

I like what I see when I look in the 2-Rarely

9.2

6

mirror (Eu gosto do que vejo 3-Sometimes

44.5

quando me olho ao espelho.)

4- Often

36.4

There are lots of things I'd change

5- Always

8.7

about my looks if I could (Se eu

1- Always

6.4

7

pudesse, mudava muitas coisas na

2- Often

23.1

3- Sometimes

33.5

minha aparência.)

4- Rarely 51

29.5

5- Never 13

7.5

1- Never

6.4

I am satisfied with my weight 2-Rarely

24.3

8

(Estou satisfeito(a) com o meu

3- Sometimes

32.9

peso.)

4- Often 39

22.5

5- Always

24

13.9

\section{1- Always}

13

7.5

There are lots of things I'd change 2-Often

39

22.5

9

10

about my looks if I could (Quem me

3- Sometimes

39.3

dera ter melhor aparência.)

4- Rarely

20.2

5- Never

10.4

1- Never

11.0

I really like what I weigh (Eu gosto

2- Rarely

25.4

mesmo do meu peso.)

3- Sometimes

32.9

4- Often

17.9

5- Always

12.7

\section{1- Always}

2.9

I wish I looked like someone else 2-Often 7.5

11

(Quem me dera ter a aparência de

3- Sometimes

24.9

outra pessoa.)

4- Rarely

29.5

5- Never

35.3

1- Never

1

0.6

People my own age like my looks 2-Rarely

9.2

(As pessoas da minha idade gostam

3- Sometimes

45.7

da minha aparência.)

4- Often

42.8

5- Always

1- Always

0.6

My looks upset me (A minha

2- Often

aparência aborrece-me.)

3- Sometimes

4- Rarely 
14

5- Never
1 - Never

I'm as nice looking as most people 2- Rarely

46
5

(Sou tão atraente quanto a maioria

3- Sometimes

29

2.9
das pessoas.)

4- Often 57

5- Always

1- Never

\section{0}

16.8

2- Rarely

3

41.6

32.9

5.8

I'm pretty happy about the way I

\section{3- Sometimes}

21

1,7

look (Estou bastante satisfeito(a)

4- Often

\section{2}

12,1 com a minha aparência.)

\section{5- Always \\ 1- Never}

I feel I weight the right amount for 2- Rarely

71

35,8

41,0

9,2

6,9

my height (Acho que tenho o peso 3-Sometimes

19,7

certo para a minha altura.)

4- Often

27,2

32,9

5- Always 13,3

\section{1- Always}

1,2

I feel ashamed of how I look (Tenho

2- Often

5,2

vergonha da minha aparência.)

3- Sometimes

20,8

4- Rarely

30,1

5- Never

1- Always

42,8

2- Often

4,0

Weighing myself depresses me

3- Sometimes

22,5

(Pesar-me deprime-me.)

4- Rarely

38,2

25,4

5- Never

9,8

1- Always

2,3

My weight makes me unhappy (O

\section{2- Often}

3- Sometimes

11,0

meu peso deixa-me infeliz.)

$$
\text { 4- Rarely }
$$

20,8

5- Never

1- Never

31,8

34,1

16,2

My looks help me to get dates (A 2-Rarely

minha aparência ajuda-me a ter 3-Sometimes

35,3

encontros amorosos.)

4- Often

19,7

5- Always

4,0

$$
\text { 1- Always }
$$

I worry about the way I look 2-Often 4,6

(Preocupo-me com a minha

3- Sometimes

aparência.)

4- Rarely

43,4

5- Never

I think I have a good body. (Eu acho 1- Never

2- Rarely

9

- Rarely 
23

I look as nice as I'd like to (Sou tão bonito(a) quanto gostaria.)
3- Sometimes

$$
\text { 4- Often }
$$

5- Always

1- Never

2- Rarely

3- Sometimes

4- Often

5- Always
83

46

7

7

30

72

53

11
48,0

26,6

4,0

4,0

17,3

41,6

30,6

6,4

Table 4 shows the items, factor loading and alpha coefficients for the three-factor solution. The first factor labelled "Appearance" consists of eight items, the second factor, labelled "Weight", consists of four items and the third factor, labelled "Attribution", consists of four items reflecting respectively general feelings about appearance, weight satisfaction and evaluative perceptions attributed to others about one's appearance.

Table 4. Factor loadings in the Portuguese BESAA (N=173).

\begin{tabular}{|c|c|c|c|c|c|}
\hline \multirow[t]{2}{*}{ Code } & \multirow[t]{2}{*}{ Item } & \multicolumn{3}{|c|}{ Factor } & \multirow[b]{2}{*}{ Total } \\
\hline & & $\begin{array}{c}\text { Appearanc } \\
\mathrm{e}\end{array}$ & $\begin{array}{c}\text { Weig } \\
\text { ht }\end{array}$ & $\begin{array}{l}\text { Attributi } \\
\text { on }\end{array}$ & \\
\hline 11 & $\begin{array}{l}\text { I wish I looked like someone else (Quem me dera } \\
\text { ter a aparência de outra pessoa.) }\end{array}$ & 0.896 & & & \\
\hline 17 & $\begin{array}{l}\text { I feel ashamed of how I look (Tenho vergonha da } \\
\text { minha aparência.) }\end{array}$ & 0.857 & & & \\
\hline 13 & $\begin{array}{l}\text { My looks upset me (A minha aparência } \\
\text { aborrece-me.) }\end{array}$ & 0.832 & & & \\
\hline 9 & $\begin{array}{l}\text { There are lots of things I'd change about my looks } \\
\text { if I could (Quem me dera ter melhor aparência.) }\end{array}$ & 0.741 & & & \\
\hline 15 & $\begin{array}{l}\text { I'm pretty happy about the way I look (Estou } \\
\text { satisfeito(a) com a minha aparência.) }\end{array}$ & 0.681 & & & \\
\hline 7 & $\begin{array}{l}\text { There are lots of things I'd change about my looks } \\
\text { if I could (Se eu pudesse. mudava muitas coisas na } \\
\text { minha aparência.) }\end{array}$ & 0.656 & & & \\
\hline 23 & $\begin{array}{l}\text { I look as nice as I'd like to (Sou tão bonito(a) quanto } \\
\text { gostaria de ser.) }\end{array}$ & 0.648 & & & \\
\hline 6 & $\begin{array}{l}\text { I like what I see when I look in the mirror (Eu gosto } \\
\text { do que vejo quando olho ao espelho.) }\end{array}$ & 0.525 & & & \\
\hline 10 & $\begin{array}{l}\text { I really like what I weigh (Eu gosto mesmo do meu } \\
\text { peso.) }\end{array}$ & & 0.939 & & \\
\hline 8 & $\begin{array}{l}\text { I am satisfied with my weight (Estou satisfeito(a) } \\
\text { com o meu peso.) }\end{array}$ & & 0.908 & & \\
\hline 16 & $\begin{array}{l}\text { I feel I weight the right amount for my height } \\
\text { (Acho que tenho o peso certo para a minha altura.) }\end{array}$ & & 0.834 & & \\
\hline 4 & I am preoccupied with trying to change my body & & 0.790 & & \\
\hline
\end{tabular}


weight (Estou preocupado(a) em tentar mudar o meu peso.)

2

12

1 Other people consider me good looking (As outras pessoas acham-me bonito(a).)

People my own age like my looks (As pessoas da minha idade gostam da minha aparência.)

I like what I look like in pictures (Gosto da minha aparência nas fotografias.)

(

Cronbach alpha

Variance
Based on the significant correlations between the primary factors and the theoretical justification of drafting a final construct built from the three primary factors, a CFA first order model was constructed. Following the modification indices, four correlations were inserted between the errors (e7-e13, e14-e15, e19-e20 and e28-e29) as can be seen in Figure 1. According to the results shown in Figure 1, the fit of the refined model was adequate for the test sample. The factor structure of the BESAA showed an unsatisfactory fit for the sample $(\lambda=.0 .61$ to $.92 ; \chi 2 / \mathrm{df}=3.062, \mathrm{CFI}=.865, \mathrm{RMR}=.097, \mathrm{GFI}=.777, \mathrm{PCFI}=$ .746, PGFI $=.607$, RMSEA = .104). We observed convergent validity for Factor Weight Satisfaction $(\mathrm{AVE}=.584)$, and Factor Appearance $(\mathrm{AVE}=.594$, values which are higher than the .5 recommended). The AVE presented low convergent validity for Factor Attribution $(\mathrm{AVE}=.442)$. Regarding the reliability validity, we observed validity for Factor Weight Satisfaction $(C R=.960)$, and Factor Appearance $(C R=.920$, where values of less than .7 are recommended). The CR presented low reliability validity for Factor Attribution $(\mathrm{CR}=.468)$. 


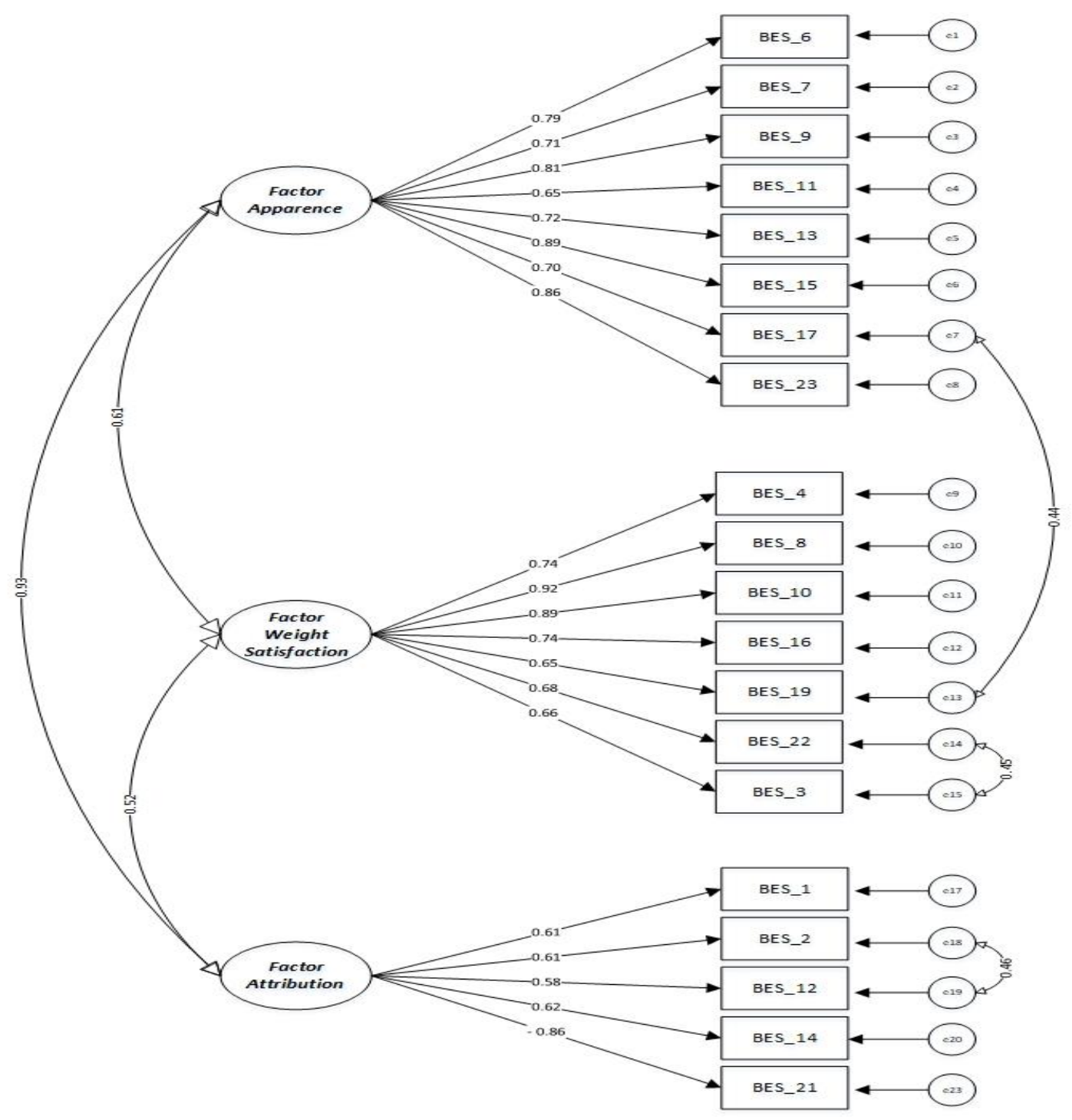

Figure 1. Factor structure of the refined first order model of the BESAA scale. $\lambda=.0 .61$ to $.92 \chi 2 / \mathrm{df}=3.062$, Comparative fit index $(\mathrm{CFI})=.865$. Root mean square error of approximation $($ RMSEA $)=.104$ fitted to the sample of Portuguese Students

Following the modification indices, seven correlations were inserted between the errors (e2-e3, e34-e4, e2-e4, e7-e13, e14-e15, e17-e18 and e18-e19) as is presented in Figure 2. According to the results shown in Figure 2, the fit of the refined model was adequate for the test sample. Adequate concurrent/divergent validity was found. Specifically, there were high correlations between theoretically similar factors, and low correlations between different factors. The fit of the BESAA to our sample $(\lambda=.61$ to $.92 ; \chi 2$ / $\mathrm{df}=2.815, \mathrm{CFI}=.884, \mathrm{RMR}=.096, \mathrm{GFI}=.801, \mathrm{PCFI}=.744, \mathrm{PGFI}=.610$, $\mathrm{RMSEA}=.103$ ) is presented in Figure 2. It is noteworthy that the following three factors provided a large contribution to the operationalization of the BESAA construct: Factor Appearance $(\beta=$ $-1.06)$, Factor Weight Satisfaction $(\beta=.58)$, and Factor Attribution $(\beta=.88)$, whose statistical evidence can be seen in Figure 2. 


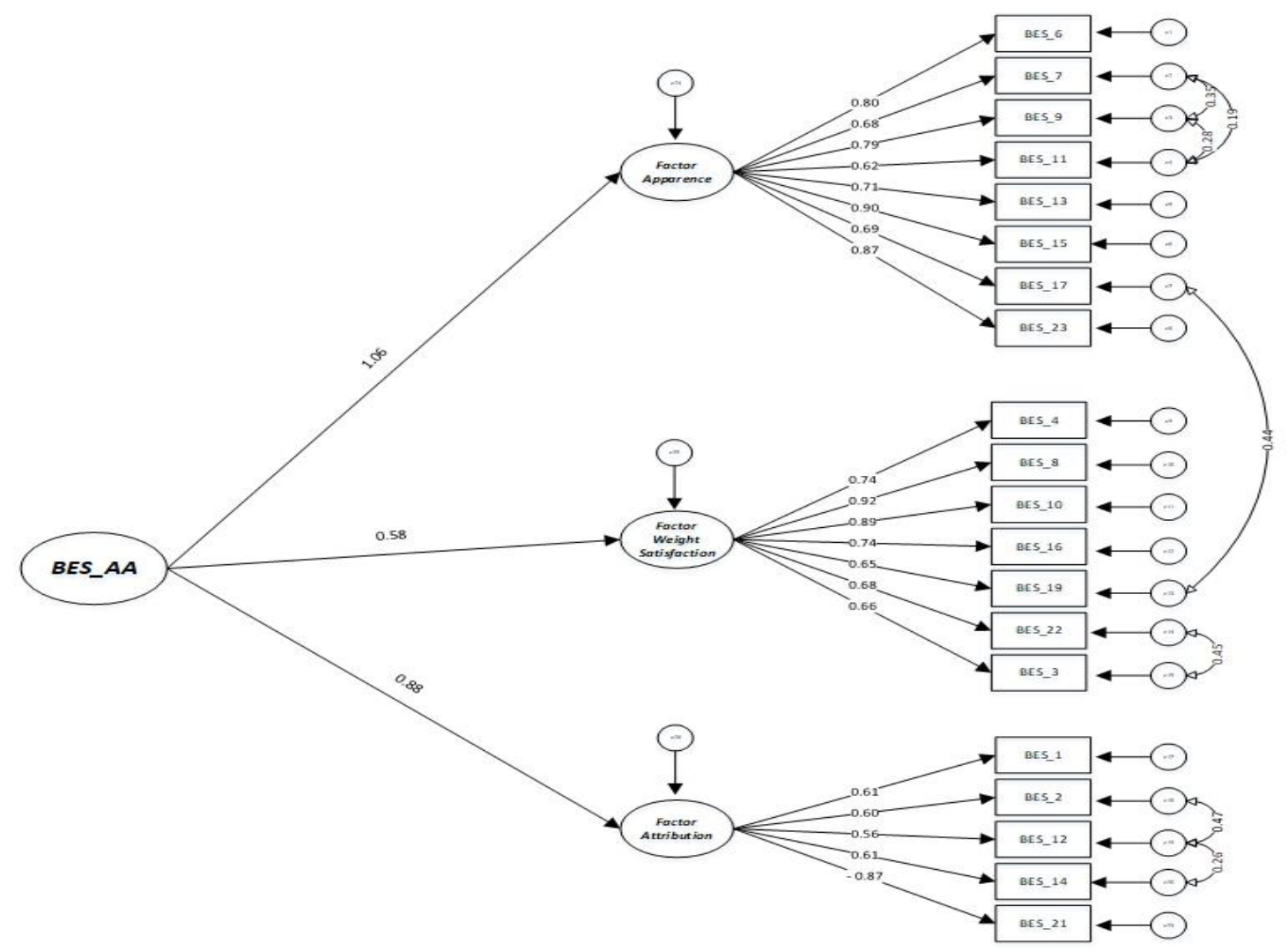

Figure 2. Factor structure of the second order hierarchical model of the BESAA scale. $\lambda=.61$ to $.92 ; \chi 2 / \mathrm{df}=2.815$, Comparative fit index $(\mathrm{CFI})=.911$. Root mean square error of approximation $(\mathrm{RMSEA})=.103$ fitted to the sample of Portuguese Students

Table 5 shows Pearson correlations between the three retained Portuguese BESAA factors and the subscales of the Appearance Schemas Inventory - Revised (ASI-R). With exception of "Motivational salience of appearance", all measurements were significantly and negatively correlated with the Portuguese BESAA factors, meaning that increased perception of levels of feelings about appearance, weight satisfaction and perceptions of what others think about their bodies were related to higher scores of BI investment. The three Portuguese BESAA factors, "Appearance", "Attribution" and "Weight", showed the highest correlations with the self-evaluative salience subscale of BI investment (-0.443, -.175 and -.216 respectively). None of the Portuguese BESAA factors were related to the ASI-R subscale labelled "motivational salience of appearance".

Table 5. Pearson correlations between Portuguese BESAA factors and scores of Appearance Schemas Inventory - Revised [ASI-R] $(\mathrm{N}=169)$.

$\begin{array}{ccc}\text { Global } & \begin{array}{c}\text { Motivational } \\ \text { salience of } \\ \text { Domain }\end{array} \\ & \text { Self-evaluative } & \end{array}$

Correlations with BESAA factors

BES (Appearance)
BES (Attribution)
BES (Weigh)

BES (Appearance)

BES (Weigh)

$\begin{array}{lll}-.391^{* *} & -.443^{* *} & -.148 \\ -.148 & -.175^{*} & -.041 \\ -.140 & -.216^{* *} & .054\end{array}$


Total $-.338^{* *}$

$-.393^{* *}$

Descriptives

Mean

3.011

2.99

3.042

SD

0.333

0.415

0.334

Note. ${ }^{* *} \mathrm{p}<.01 ;{ }^{*} \mathrm{p}<.05$

The comparison between males and females showed significant differences in all Portuguese BESAA factors except in "Weight" factor (see Table 6). The female participants were less satisfied with their "Appearance" and "Attribution" than males. However, no differences were found regarding the "Weight" factor. These data show that females are more vulnerable when it comes to their perceptions of their own appearance and about the opinions attributed by others about their body.

Table 6. Gender difference in Portuguese BESAA

\begin{tabular}{lccccc}
\hline & \multicolumn{2}{c}{ Male } & \multicolumn{3}{c}{ Female } \\
\hline Portuguese BESAA & Mean & SD & Mean & SD & $t$ \\
\hline Appearance & 21.3 & 5.9 & 19.0 & 6.3 & $2.4^{*}$ \\
Atribution & 9.5 & 3.6 & 7.7 & 4.0 & $2.9^{* *}$ \\
Weigh & 7.1 & 2.2 & 7.1 & 1.6 & n.s. \\
Total & 35.6 & 8.6 & 31.5 & 9.8 & $2.8^{* *}$ \\
\hline
\end{tabular}

Note. ${ }^{*} \mathrm{p}<.05 ;{ }^{* *} \mathrm{p}<.01$

The comparison between areas of study showed significant differences only in the "Attribution" factor (see Table 7) with participants from the area of health being less satisfied than other participants about the attributions of positive evaluations about their body and appearance. With regard to "Weight" and "Appearance" factors, no differences were found.

Table 7. Scientific area differences in Portuguese BESAA

\begin{tabular}{|c|c|c|c|c|c|c|c|c|}
\hline \multirow[b]{2}{*}{ BES-15 } & & \multicolumn{2}{|c|}{$\begin{array}{c}\text { Technical and } \\
\text { natural sciences }\end{array}$} & \multicolumn{2}{|c|}{$\begin{array}{c}\text { Human and social } \\
\text { sciences }\end{array}$} & \multicolumn{2}{|c|}{ Health sciences } & \multirow[b]{2}{*}{$F(\mathrm{a})$} \\
\hline & & Mean & $\mathrm{SD}$ & Mean & $\mathrm{SD}$ & Mean & $\mathrm{SD}$ & \\
\hline & Appearance & 21.1 & 5.8 & 19.2 & 7.3 & 19.0 & 6.2 & 2.3 \\
\hline & Attribution & 9.2 & 3.5 & 8.5 & 4.4 & 7.6 & 4.1 & $3.1^{*}$ \\
\hline & Weigh & 7.1 & 2.0 & 7.4 & 1.6 & 7.0 & 1.9 & 0.4 \\
\hline & Total & 35.1 & 8.0 & 32.5 & 10.6 & 31.4 & 10.2 & 2.9 \\
\hline
\end{tabular}

Note. * $\mathrm{p}<.05$; (a) Anova Test

\section{Discussion}

To our knowledge, this is the first study about psychometric properties of the BESAA [16] that used a sample of young adults [14] in a specific context: a university. The results of this study contribute to existing scientific evidence [14-19] which confirms the reliability and validity of the BESAA by showing that it is an instrument which can also 
be used with Portuguese university students. After having translated and adapted it to be culturally relevant, we estimated the psychometric properties of the BESAA using a confirmatory factor analysis.

In this study, the response to the BESAA was completed online, given the ease with which young people today deal with technology. It is believed that this methodology may have contributed to a more appealing and practical medium for the respondents, as well as being safer since the risk of paper loss, errors due to incorrect insertion of data and insincere or less developed answers if delivered by hand is nil or less likely. As the response rate in face-to-face interviews and email (33.8\%) [8] is low among university students in Portugal, an online platform of data collection was presented and available in classrooms that had been previous approved for the completion of the BESAA.

In this present study, the process of translation and cross-cultural adaptation of the BESAA into Portuguese was described, considering the methodological rigor advocated in the international guidelines [24]. In addition to methodological approaches based on the relevant literature, discussions with health workers (one physiotherapist and one nurse) and participants in the pre-test provided appropriate conceptual evidence of the impact of BI and appearance in the young academic population. All items were considered relevant to the population and semantic equivalence was established by forward translation to identify sets of words or expressions and verb tenses that were difficult to understand, such as "would help me get a job", ' looked better', "looking as most people", 'pretty happy" and "to get dates". In these cases, the original and back-translated versions were compared, and after discussion and consensus with experts the most appropriate words and expressions, confirmed by the pre-test with students from another university, were used.

Since the entire range of responses was used in responding to all items with varying frequency, it can be said that the 5-point Likert scale was a suitable method for response collection. However, in almost all the questions, the majority of the participants chose the middle option responses, namely option 2 or 4 (rarely or often) and option 3 (sometimes). The only exception is item 11 ("I wish I looked like someone else") where the highest proportion (35.3\%) of responses was option 5 (never).

In fact, the Likert-type response has long been known by researchers [33] to induce the respondent to focus on the central options, which produce an "anchor effect".

The CAPTCA analysis revealed a three-factor model, reflecting feelings about appearance, weight satisfaction and valuations about what other people think about their bodies. The first factor was labelled "Appearance", the second factor "Weight", indicated satisfactory internal consistency of the scale, according to the recommended criteria $(>0.70)$ [34] and were like those found in previous studies with similar objectives [14, 16-17].

Moreover, the items attributed to each of the subscales did not change with respect to the original (Canadian) version of Mendelson \& Mendelson [16], the Italian version [17], and the US version in two of the subscales, namely "Weight" and Appearance" [19]. The exception was item 1 ("I like what I look in Pictures"), which in this study is part of the "Attribution" subscale, while in the original and Italian versions is part of the "Appearance" subscale. This change may be based on the perception that participants have of the image transmitted to others because in the modern world, where there is a greater dissemination of images through social networks such as Instagram, photos can contribute as a strategy to promote BI. In this way, the image that is transmitted through photography can be perceived as a form of evaluation by others. To better explore this hypothesis, in future studies it would be interesting to verify the correlation between the perception of BI and the influence of social network usage, in particular Instagram. Another explanation may be related to age because in this study age mean is higher than other studies [16-17, 19].

As recommended by the authors of the original scale, the questionnaire used in this study was analyzed in the pre-test in order to verify its operation in conjunction with the ASI-R. This procedure allowed us to corroborate Mendelson \& Mendelson's conclusion 
[16], since the BESAA, can be used in combination with other questionnaires with minimal difficulty and more practical implementation on the Portuguese population.

The considerably low levels of BI investment found in the ASI-R subscales may be explained by the fact that participants were satisfied with their body. This result seems to confirm that more than a third $(35.3 \%)$ of participants would not want to look like someone else.

As expected, all factors from the Portuguese BESAA and the BI investment (ASI-R) domains were negatively correlated, indicating discriminative validity. This evidence allows us to say that Portuguese students do not invest in their physical appearance or this investment does not have psychopathological significance in this case. Considering that the self-evaluative salience sub-scale of appearance has frequently been associated with several psychopathological manifestations, low scores in this variable are of important clinical significance, because it can be concluded that this sample presents no problems in this domain. On the other hand, the second subscale, known as motivational salience, does not appear to be an index of psychopathology, even if the results were high. As in this study the results for this factor are low, it means that these participants do not present psychopathological problems.

Regarding the participants' area of study, no significant differences were found in the Portuguese BESAA average subscales (except for the "Attribution" subscale). This evidence points to the students' areas of study having no influence on feelings underlying their BI, since the results were similar across the various areas. However, no studies were found with university students that included the variables Academic Year and Academic Area and their association with BI dissatisfaction, resulting in the discussion of these results being inconclusive to some extent.

The main limitation of this study regards the ages of the participants. The mean age of the sample in this study differs from the mean age of the original version [16]. This may have altered the data obtained in the scale since throughout a person's life, their perceptions of themselves may change, resulting in alterations related to perception of BI [35-37]. However, the age group considered here, could be regarded as a strength and not a weakness due to the lack of studies in the literature concerning adults in validity of the BESAA [14]. Another limitation is the sample size, because is smaller than original study and others carried out within the same area [16-17, 19]. However, the minimum sample size needed to validate an instrument of measurement has been considered, thus leading to the conclusion that the sample size does support the construct validity of these measurements [25-26].

\section{Conclusions}

The Portuguese BESAA has achieved semantic, item, conceptual, operational and measurement equivalences which are like the original BESAA. While there are small differences for this population, the Portuguese BESAA showed adequate validity and reliability and may be used to assess the self-evaluation of one's body or appearance and can be considered a good instrument to evaluate body satisfaction in young Portuguese adults.

Author Contributions: Author Contributions: M.P.B. and A.P. conceived the study, developed the survey protocol and arranged for data collection. V.L. and M.P.B. did the statistics and did the analysis. M.G., V.L. and M.P.B. wrote the draft for the paper. All authors commented the manuscript. M.P.B. refined the manuscript for submission.

Funding: This article was supported by National Funds through FCT - Fundação para a Ciência e a Tecno-logia within CINTESIS, R\&D Unit (reference UIDB/4255/2020).

Institutional Review Board Statement: The study was conducted according to the guidelines of the Declaration of Helsinki and approved by the Ethics and Deontology Committee of University of Aveiro (Process number: 9/2016). 
Informed Consent Statement: Informed consent was obtained from all subjects involved in the study.

Data Availability Statement: The datasets analyzed in this study are not publicly available but are available on request from the corresponding author.

Acknowledgments: The dataset has been collected with the support of Rita Pinto (master student at University of Aveiro)

Conflicts of Interest: The authors declare no conflict of interest.

\section{References}

1. Cheah, W. L.; Hazmi, H.; Chang, C. T., Disordered eating and body image issues and their associated factors among adolescents in urban secondary schools in Sarawak, Malaysia. Int J Adolesc Med Health 2017, 29 (2), 10.1515/ijamh-2015-0044

2. Kuek, A.; Utpala, R.; Lee, H. Y., The clinical profile of patients with anorexia nervosa in Singapore: a follow-up descriptive study. Singapore Med J 2015, 56 (6), 324-8, 10.11622/smedj.2015090

3. Goncalves, S.; Machado, B. C.; Martins, C.; Hoek, H. W.; Machado, P. P., Retrospective Correlates for Bulimia Nervosa: A Matched Case-Control Study. Eur Eat Disord Rev 2016, 24 (3), 197-205, 10.1002/erv.2434

4. McCabe, M. P.; Connaughton, C.; Tatangelo, G.; Mellor, D.; Busija, L., Healthy me: A gender-specific program to address body image concerns and risk factors among preadolescents. Body Image 2017, 20, 20-30, 10.1016/j.bodyim.2016.10.007

5. Becker, I.; Nieder, T. O.; Cerwenka, S.; Briken, P.; Kreukels, B. P.; Cohen-Kettenis, P. T.; Cuypere, G.; Haraldsen, I. R.; Richter-Appelt, H., Body Image in Young Gender Dysphoric Adults: A European Multi-Center Study. Arch Sex Behav 2016, 45 (3), 559-74, 10.1007/s10508-015-0527-z

6. Laus, M. F.; Costa, T. M.; Almeida, S. S., Gender differences in body image and preferences for an ideal silhouette among Brazilian undergraduates. Eat Behav 2015, 19, 159-62, 10.1016/j.eatbeh.2015.09.003

7. Senin-Calderon, C.; Rodriguez-Testal, J. F.; Perona-Garcelan, S.; Perpina, C., Body image and adolescence: A behavioral impairment model. Psychiatry Res 2017, 248, 121-126, 10.1016/j.psychres.2016.12.003

8. Brandao, M. P.; Pimentel, F. L.; Silva, C. C.; Cardoso, M. F., Risk factors for cardiovascular disease in a Portuguese university population. Rev Port Cardiol 2008, 27 (1), 7-25,

9. Brandao, M. P.; Pimentel, F. L.; Cardoso, M. F., Impact of academic exposure on health status of university students. Rev Saude Publica 2011, 45 (1), 49-58,

10. Fernandez, A.; Howse, E.; Rubio-Valera, M.; Thorncraft, K.; Noone, J.; Luu, X.; Veness, B.; Leech, M.; Llewellyn, G.; Salvador-Carulla, L., Setting-based interventions to promote mental health at the university: a systematic review. Int J Public Health 2016, 61 (7), 797-807, 10.1007/s00038-016-0846-4

11. Latimer, L. A.; Velazquez, C. E.; Pasch, K. E., Characteristics and behaviors of non-overweight college students who are trying to lose weight. J Prim Prev 2013, 34 (4), 251-60, 10.1007/s10935-013-0309-0

12. Musaiger, A. O.; Al-Mannai, M., Association between exposure to media and body weight concern among female university students in five Arab countries: a preliminary cross-cultural study. J Biosoc Sci 2014, 46 (2), 240-7, $10.1017 /$ S0021932013000278

13. Lôbo, I. L. B.; Mello, M. T. d.; Oliveira, J. R. V. d.; Cruz, M. P.; Guerreiro, R. d. C.; Silva, A., Body image perception and satisfaction in university students. Revista Brasileira de Cineantropometria \& Desempenho Humano 2020, 22,

14. Kling, J.; Kwakkenbos, L.; Diedrichs, P. C.; Rumsey, N.; Frisén, A.; Brandão, M. P.; Silva, A. G.; Dooley, B.; Rodgers, R. F.; Fitzgerald, A., Systematic review of body image measures. Body Image 2019, 30, 170-211, 10.1016/j.bodyim.2019.06.006

15. Franko, D. L.; Jenkins, A.; Roehrig, J. P.; Luce, K. H.; Crowther, J. H.; Rodgers, R. F., Psychometric properties of measures of eating disorder risk in Latina college women. Int J Eat Disord 2012, 45 (4), 592-6, 10.1002/eat.20979

16. Mendelson, B. K.; Mendelson, M. J.; White, D. R., Body-esteem scale for adolescents and adults. J Pers Assess 2001, 76 (1), 90-106, 10.1207/S15327752JPA7601_6

17. Confalonieri, E.; Gatti, E.; Ionio, C.; Traficante, D., Body esteem scale: a validation on italian adolescents. Testing, Psychometrics, Methodology in Applied Psychology 2008, 15 (3), 153-165,

18. Jonsdottir, B., [Icelandic Medical Association a professional organisation and a Trade Union. IMA s collective bargaining for 90 years]. Laeknabladid 2008, 94 (9), 579,

19. Cragun, D.; DeBate, R. D.; Ata, R. N.; Thompson, J. K., Psychometric properties of the Body Esteem Scale for Adolescents and Adults in an early adolescent sample. Eat Weight Disord 2013, 18 (3), 275-82, 10.1007/s40519-013-0031-1

20. Nazaré, B.; Moreira, H.; Canavarro, M. C., Uma perspectiva cognitivo-comportamental sobre o investimento esquemático na aparência : Estudos psicométricos do Inventário de Esquemas sobre a Aparência - Revisto ( ASI-R ). Laboratório de Psicologia 2010, 8 (1), 21-36,

21. Torres-McGehee, T. M.; Monsma, E. V.; Dompier, T. P.; Washburn, S. A., Eating disorder risk and the role of clothing in collegiate cheerleaders' body images. J Athl Train 2012, 47 (5), 541-8, 10.4085/1062-6050-47.5.03

22. Dyer, A.; Borgmann, E.; Feldmann, R. E., Jr.; Kleindienst, N.; Priebe, K.; Bohus, M.; Vocks, S., Body image disturbance in patients with borderline personality disorder: impact of eating disorders and perceived childhood sexual abuse. Body Image 2013, 10 (2), 220-5, 10.1016/j.bodyim.2012.12.007 
23. Alleva, J. M.; Martijn, C.; Veldhuis, J.; Tylka, T. L., A Dutch translation and validation of the Body Appreciation Scale-2: An investigation with female university students in the Netherlands. Body Image 2016, 19, 44-48, 10.1016/j.bodyim.2016.08.008

24. Muniz, J.; Elosua, P.; Hambleton, R. K., [International Test Commission Guidelines for test translation and adaptation: second edition]. Psicothema 2013, 25 (2), 151-7, 10.7334/psicothema2013.24

25. Pestana, M. H.; Gageiro, J. N., Análise de Dados para Ciências Sociais - A Complementariedade do SPSS 6ed.; Edições Silabo: 2014.

26. Cohen, J., Statistical power analysis for the behavioral sciences. . 2 ed.; Hillsdale, N.J. : L. Erlbaum Associates: 1988.

27. Brislin, R. W., Back-translation for cross-cultural research. Journal of Cross-Cultural Psychology 1970, 1 (3), 185-216, 10.1177/135910457000100301

28. Brislin, R. W., The wording and translation of research instruments. In Field methods in cross-cultural psychology, W.J. Lonner; J.W. Berry, Eds. Sage Publications: Newbury Park CA, 1986, pp 137-164.

29. Kline, P., The handbook of psychological testing 2ed.; Routledge: London, 2000, p 744.

30. Linting, M.; van der Kooij, A., Nonlinear principal components analysis with CATPCA: a tutorial. J Pers Assess 2012, 94 (1), 12-25, 10.1080/00223891.2011.627965

31. Cash, T. F.; Melnyk, S. E.; Hrabosky, J. I., The assessment of body image investment: an extensive revision of the appearance schemas inventory. Int J Eat Disord 2004, 35 (3), 305-16, 10.1002/eat.10264

32. Marôco, J., Análise Estatística com o SPSS Statistics. 8 ed.; Sílabo: Lisboa, 2018, p 1022.

33. Hair, J. F.; Black, W. C.; Babin, B. J.; Anderson, R. E., Multivariate Data Analysis. Pearson Education Limited: 2013.

34. Springer, A. E.; McQueen, A.; Quintanilla, G.; Arrivillaga, M.; Ross, M. W., Reliability and validity of the Student Perceptions of School Cohesion Scale in a sample of Salvadoran secondary school students. BMC Int Health Hum Rights 2009, 9, 30, 10.1186/1472-698X-9-30

35. Terwee, C. B.; Bot, S. D.; de Boer, M. R.; van der Windt, D. A.; Knol, D. L.; Dekker, J.; Bouter, L. M.; de Vet, H. C., Quality criteria were proposed for measurement properties of health status questionnaires. J Clin Epidemiol 2007, 60 (1), 34-42, 10.1016/j.jclinepi.2006.03.012

36. Bearman, S. K.; Martinez, E.; Stice, E.; Presnell, K., The Skinny on Body Dissatisfaction: A Longitudinal Study of Adolescent Girls and Boys. J Youth Adolesc 2006, 35 (2), 217-229, 10.1007/s10964-005-9010-9

37. Cash, T. F.; Fleming, E. C.; Alindogan, J.; Steadman, L.; Whitehead, A., Beyond body image as a trait: the development and validation of the Body Image States Scale. Eat Disord 2002, 10 (2), 103-13, 10.1080/10640260290081678

38. Kruger, J.; Lee, C. D.; Ainsworth, B. E.; Macera, C. A., Body size satisfaction and physical activity levels among men and women. Obesity (Silver Spring) 2008, 16 (8), 1976-9, 10.1038/oby.2008.311 